\title{
Three-dimensional printed complete denture fabrication using the scan data from the conventional denture-making process
}

\author{
Hyun-Min Kim¹, Jong-Jin Kim¹, Joo-Hee Lee ${ }^{1,2}$, Hyun-Suk Cha ${ }^{1,2}$, Jin Baik ${ }^{1 *}$ \\ 'Division of Prosthodontics, Department of Dentistry, Asan Medical Center, Seoul, Republic of Korea \\ 'Division of Prosthodontics, Department of Dentistry, Asan Medical Center, College of Medicine, University of Ulsan, Seoul, \\ Republic of Korea
}

Recently three-dimensional (3D) printed complete dentures are becoming more widely recognized as one of the treatment options for the edentulous patients. Korean National Healthcare, however, has not yet approved the application of the 3D printed dentures, and in the cases where the dentures should be refabricated, the conventional fabrication process needs to be entirely repeated. However, during the conventional process, the digital scan data of some key steps could be easily obtained. In this clinical case, using these data, a new pair of 3D printed dentures that improved the limitations of the first conventional dentures were successfully fabricated. (J Dent Rehabil Appl Sci 2020;36(3):196-202)

Key words: complete denture; 3D printing; functional impression; digital scan

\section{서론}

의료 분야에서의 3D 프린팅 활용에 대한 연구는 2010 년대부터 가속화되기 시작하였고, 이와 함께 치의학 영 역에서도 3D 프린팅을 활용하기 위한 연구가 현재까지 활발하게 이루어지고 있다. 최근 $3 \mathrm{D}$ 프린팅을 활용한 총의치 제작이 주목을 받고 있는데, Stereolithography, Rapid prototyping, Digital light processing 등의 방식이 주로 연구되어 사용되고 있다. ${ }^{2-4}$

현재 전세계적으로 상용화되어 있는 3D printed denture 시스템으로는 DENTCA CAD/CAM denture (DENTCA Inc., Los Angeles, USA)가 대표적이다. ${ }^{5}$ 그러나 3D 프 린팅 의치상과 인공치 간 접착이 통상적인 열중합 레진을 활용한 방식에 비해 접착강도가 낮으므로 인공치가 더 쉽게 탈락할 수 있으며, 3D 프린팅 의치상이 열중합 레진

${ }^{*}$ Correspondence to: Jin Baik

Clinical professor, Division of Prosthodontics, Department of Dentistry,

Asan Medical Center, 88 Olympic-ro 43-gil, Songpa-gu, Seoul, 05505, Republic of Korea

Tel: +82-2-3010-5815, Fax: +82-2-3010-6967, E-mail: baikjin@amc.seoul.kr

Received: June 15, 2020/Last Revision: July 2, 2020/Accepted: July 23, 2020
의치상에 비해 굴곡강도 및 파괴인성이 낮아 파절에 더 취약하다는 단점이 현재까지는 존재한다. ${ }^{6,7}$ 그럼에도 불 구하고 $3 \mathrm{D}$ 프린팅을 활용한 의치 제작은 전통적인 방식 과 비교 시 향상된 조직 표면 적합도 및 물리적인 유지력, 의치 재제작의 용이성, 단축된 치료 기간 등과 같은 차별 화된 장점들이 존재하여 활용이 점차 증가하고 있는 추 세이다. ${ }^{4}$

DENTCA 시스템의 경우 후방부를 분리할 수 있는 전 용 트레이, 교합 및 하악 운동을 기록할 수 있게 하는 중 심핀과 트레이서 등 전용 장치 및 작업과정이 존재한다. ${ }^{8}$ 그러나 본 증례에서는 보험 총의치와 같이 전통적인 방 식의 의치 제작 과정에서 간단하게 저장해둘 수 있는 스 캔 정보를 활용하여 $3 \mathrm{D}$ 프린팅 방식의 의치 제작을 위해 DENTCA 시스템의 디지털 제작과정을 효과적으로 접 목시킨 증례에 대해 소개하고자 한다. 


\section{증례보고}

본 증례는 65 세의 남자 환자로 기존 상하악 총의치를 분실하여 새로운 의치를 제작하고 싶다는 주소로 내원하 였다. 또한 재분실에 대한 심한 우려 때문에 보험 총의치 제작과 동시에 추가적인 의치 제작을 원하였다. 임상 및 방사선학적 검사 시 중등도의 치조제 흡수 양상이 관찰 되었다(Fig. 1, 2). 우선 통상적인 방식의 보험 총의치 제 작을 계획하였으며, 동시에 이 기공과정 중 최종모형과 납의치를 디지털 스캔 데이터로 저장하여 3D 프린팅을 통한 의치 제작에 활용하기로 하였는데, 이는 환자가 먼 지역에 거주하여 내원 횟수를 최소화하기 위한 목적이었 다.

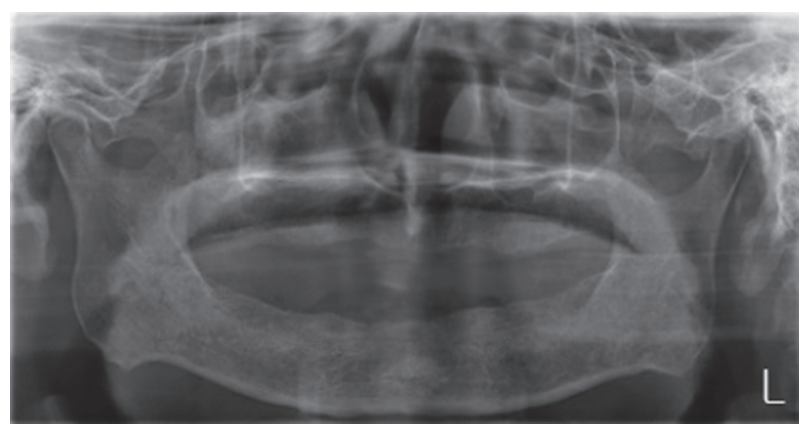

Fig. 1. Initial panoramic radiograph.
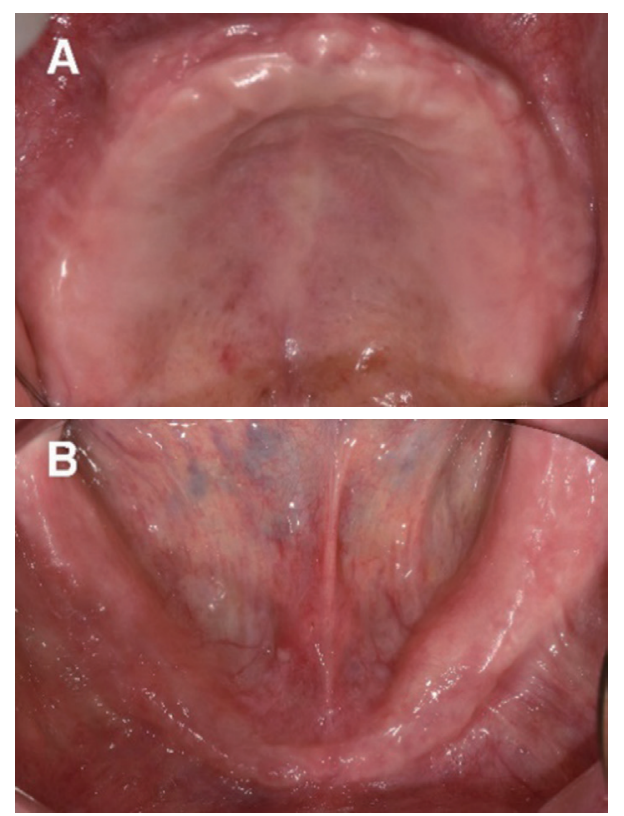

Fig. 2. Initial intraoral photographs. (A) Maxillary view, (B) Mandibular view.
1 차 의치 제작은 통상적인 보험 총의치 제작 과정에 준 하여 진행하였다. 진단모형에서 자가중합형 아크릴릭 레 진(SR Ivolen, Ivoclar Vivadent AG, Schaan, Liechtenstein)으로 개인트레이를 제작하였으며, 모델링 컴파운 드(Peri Compound, GC Corporation, Tokyo, Japan)로 변연형성 후 polyvinyl siloxane (PVS, Examixfine, GC Corporation) 인상재로 최종인상을 채득하여 최종모형 을 제작하였다(Fig. 3). 최종모형 상에서 제작한 왁스림을 시적 및 조절하고 안궁이전 시행 후 악간관계를 기록하 였다(Fig. 4). 이를 활용하여 최종모형을 반조절성 교합기 (KaVo PROTARevo articulator, KaVo Dental GmbH, Biberach, Germany) 상에 마운팅 후 인공치 배열하여 납 의치 제작하였고, 시적을 통해 입술지지, 전치부 형태 및 노출도 등에 대해 환자와 상의하여 수정하였다(Fig. 5).

이 단계에서 추후 $3 \mathrm{D}$ printed denture 제작을 위해 상 하악 최종모형과 납의치를 각각 교합기에 마운팅한 상 태로 모델스캐너를 사용하여 스캔하였고 STL 파일로 저 장해두었다(Fig. 6). 이후 Lucitone 199 (Dentsply, York, USA)으로 레진전입 및 열중합하여 첫번째 의치를 완성 하였다(Fig. 7).

다음은 2 차 의치 제작을 위해 최종모형 및 납의치의 스 캔 파일을 computer-aided design (CAD) 소프트웨어 상 에서 중첩 후 활용하여 디지털 방식으로 제작할 의치의 디자인을 완성하였다(Fig. 8). 인공치 배열 시 첫번째 의치 의 전치부 및 전체적인 악궁 형태를 반영하여 완성 후 시
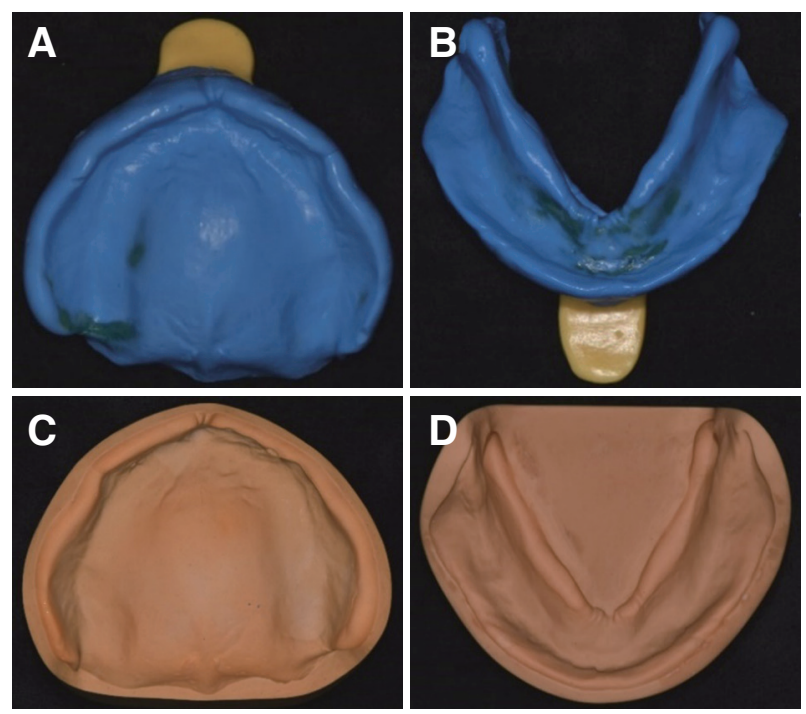

Fig. 3. (A), (B) Definitive impressions, (C), (D) Definitive stone casts. 

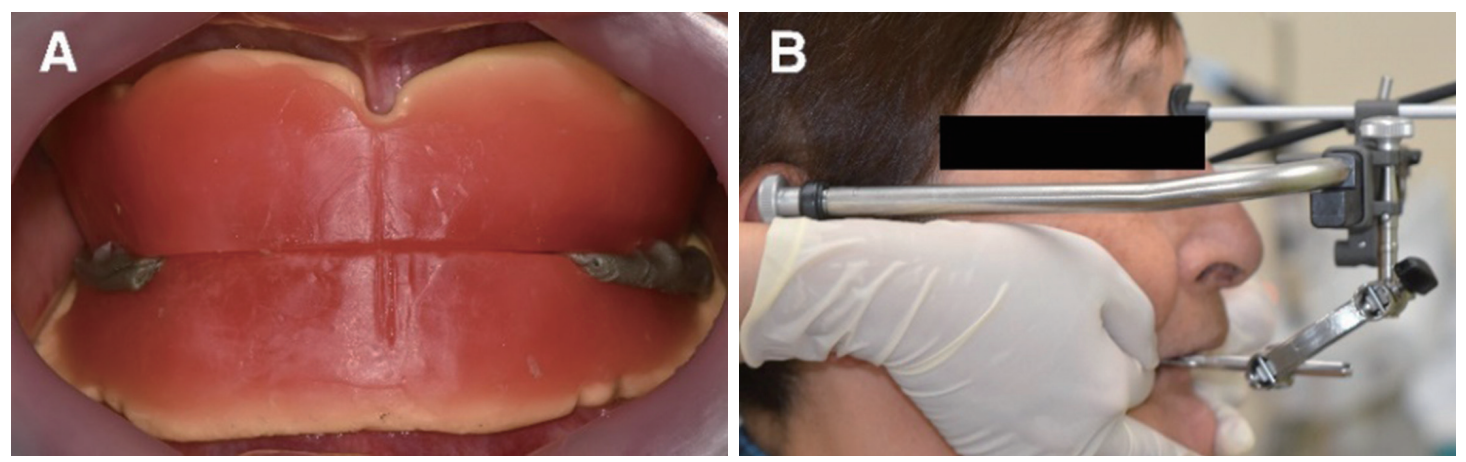

Fig. 4. (A) Vertical \& horizontal jaw relation record, (B) Facebow transfer.
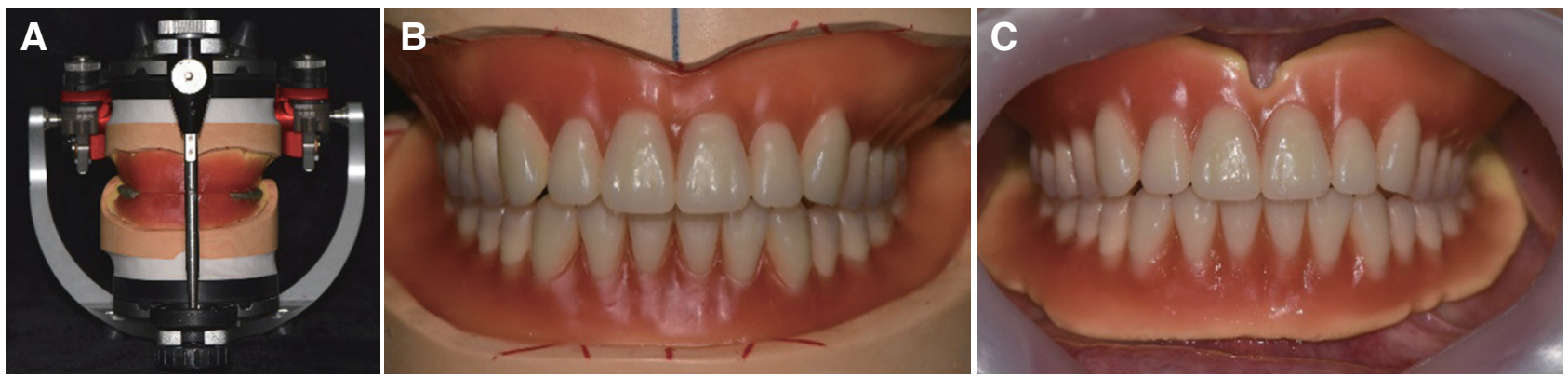

Fig. 5. (A) Mounting of definitive casts on the articulator, (B) Mounted wax dentures, (C) Wax denture try-in.
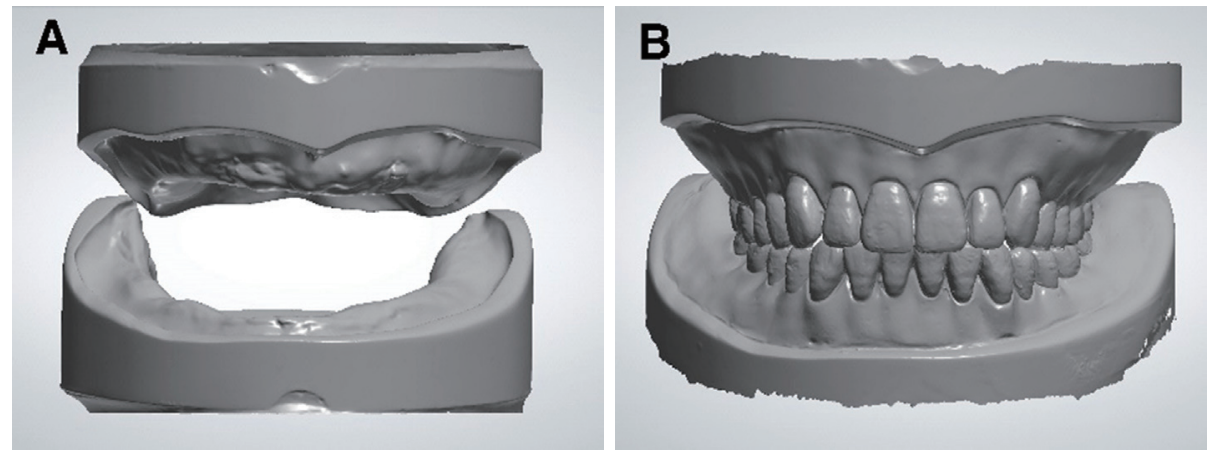

Fig. 6. Scan data. (A) Definitive casts mounted on the articulator, (B) Wax dentures mounted on the articulator.
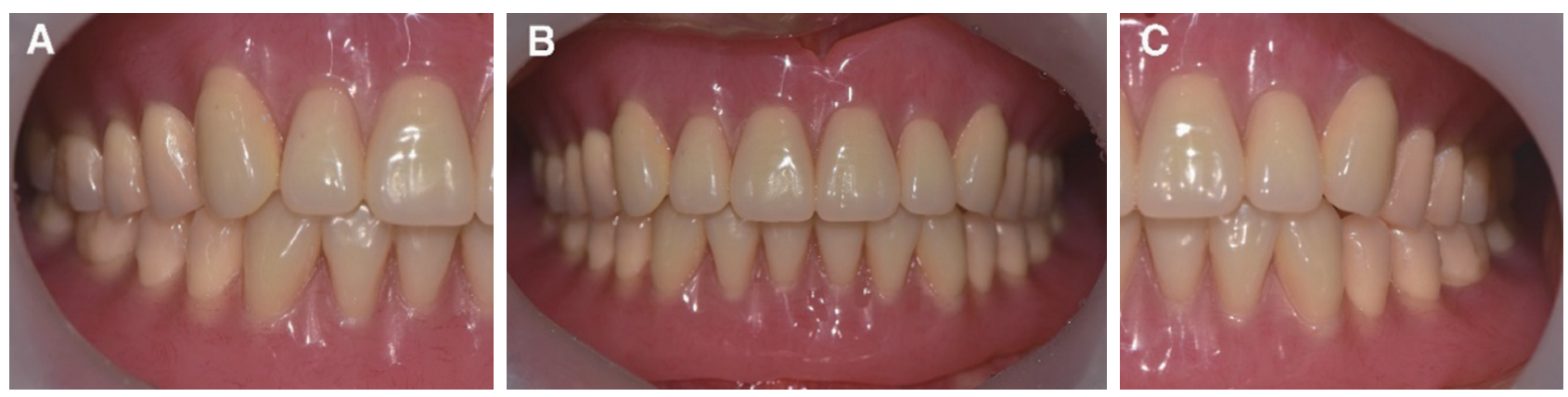

Fig. 7. Intraoral view of conventional dentures. (A) Right lateral view, (B) Frontal view, (C) Left lateral view. 
적의치를 $3 \mathrm{D}$ 프린팅하였다.

$3 \mathrm{D}$ 프린팅 시적의치를 구강 내 시적 및 조절하여 반복 적으로 재현 가능한 균등한 교합접촉을 확인하였고, 악 궁 형태 및 치아 배열 등을 확인하였다. 또한 다소 개선이 필요하다고 판단되었던 하악 의치의 설측 변연 및 구후 융기부 변연 부위에 모델링 컴파운드를 사용하여 부분적 으로 변연형성을 시행하였다(Fig. 9A, 9B). 이후 상하악 시적의치 내면에 PVS 인상재(Imprint 3 Light Body, 3M Deutschland GmbH, Neuss, Germany)를 도포하여 폐 구 상태에서 기능인상을 채득한 후, 실리콘 교합인기재 (Occlufast Rock, Zhermack S.p.A., Polesine, Italy)로 교 합관계를 기록하였다(Fig. 9C, 9D).

새롭게 인상채득한 시적의치의 조직면과 상하악 교합 관계를 스캔하여 $\mathrm{CAD}$ 프로그램 상에서 의치 디자인 수 정 후 최종 형태의 의치상을 $3 \mathrm{D}$ 프린팅하였다. 인공치
는 전치부와 양측 구치부로 나누어 각각 $3 \mathrm{D}$ 프린팅하였 고 전용 접착제를 사용하여 의치상과 결합 후 연마하여 완성하였다(Fig. 10A, 10B). 이 후 환자의 두번째 내원 시 성공적으로 $3 \mathrm{D}$ printed denture 치료를 완료하였다(Fig. 10C).

\section{고찰}

현재까지는 건강보험 총의치 제작을 위해서 통상적인 방식을 사용해야 한다는 제약이 존재한다. 그러나 본 증 례와 같이 통상적인 제작과정 중의 특정 정보를 간단히 스캔하여 $3 \mathrm{D}$ 데이터로 저장해둘 경우, 틀니의 재제작 필 요 시 1 - 2회 내원만으로 3D 프린팅을 활용하여 새로운 의치를 간편하게 완성할 수 있다. 제작 과정 중 시적의치 를 활용하는 경우 정중선과 교합평면이 적절한지, 중심
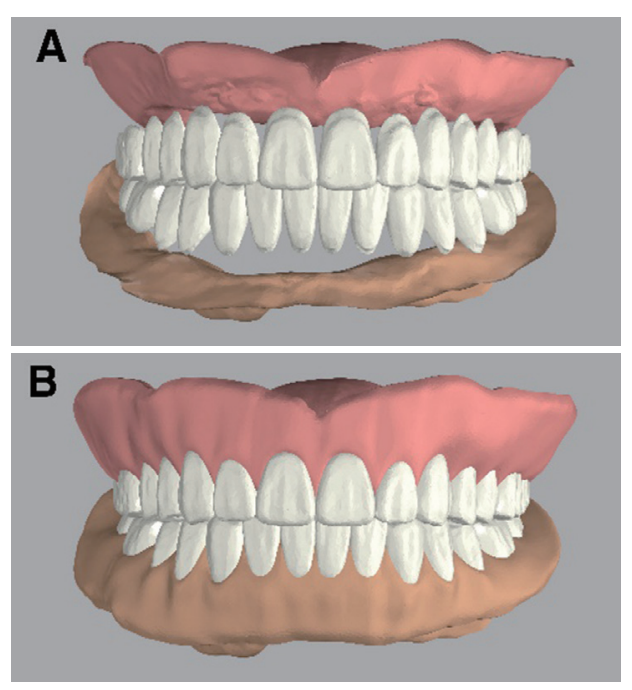

Fig. 8. CAD process. (A) Digital denture teeth arrangement, (B) 3D complete denture design.
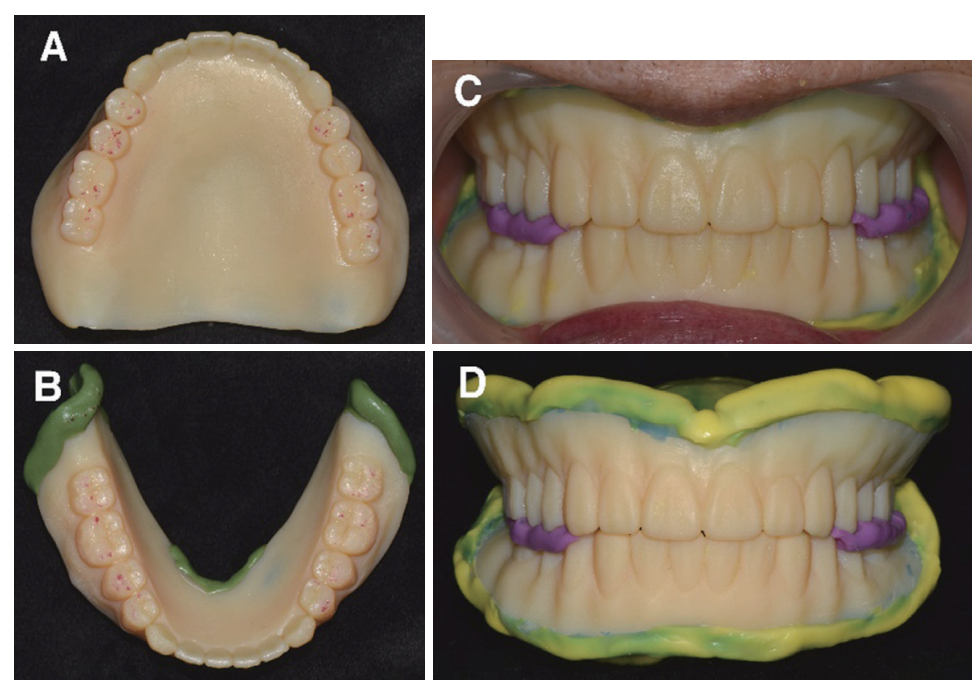

Fig. 9. (A), (B) Occlusal adjustments and border modifications on tryin dentures, (C), (D) Closed-mouth, functional impression and bite registration using try-in dentures.
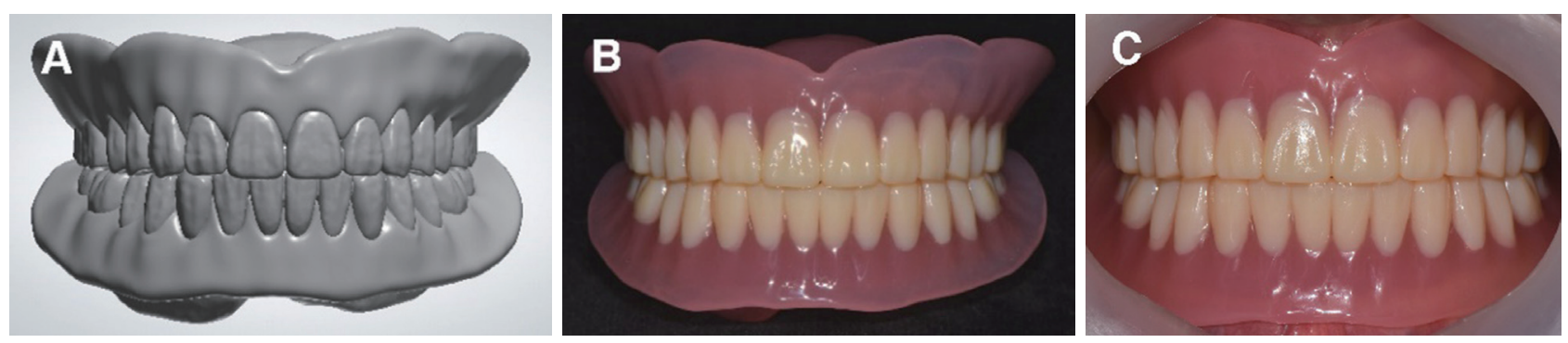

Fig. 10. (A) Final denture design on the CAD software, (B) Fabrication of the 3D printed definitive dentures, (C) Intraoral view. 
위에서 교합이 정확히 이루어지는지 등을 평가할 수 있 고, 전치부 형태 및 배열, 상순 지지, 발음 등과 관련된 환 자 만족 여부를 의치 완성 전에 확인할 수 있기 때문에 해 당 단계를 생략하지 않고 진행하는 것이 추천된다. ${ }^{8}$

또한 납의치의 스캔 정보가 $3 \mathrm{D}$ 프린팅을 활용한 의치 제작을 위해 사용되었는데 이는 좀 더 일반적인 왁스림 의 스캔과 비교하여 추가적인 장점을 가진다. 왁스림과 마찬가지로 납의치는 수직 및 수평적 악간관계, 입술지 지 등에 대한 정보를 포함하는 것뿐만 아니라, 원하는 상 하악 전치부의 수직 및 수평 피개 정도를 왁스림보다 좀 더 직관적으로 시각화할 수 있고 이상적인 인공치의 형 태 및 악궁 상에서의 3 차원적 배열 등을 전달하는데 유리 하다. ${ }^{9}$ 또한 왁스림 스캔의 경우 베이스 플레이트 왁스의 반투명한 특성 때문에 정확한 인식을 위해서 스캔용 파 우더를 도포해야 하지만, 납의치의 경우 레진 인공치가 쉽게 스캔되기 때문에 작업과정이 좀 더 깨끗하고 용이 하다는 장점이 있다.

또한 본 증례에서는 앞서 제작한 전통적 방식의 총의 치에서 부적절하거나 미흡하다고 판단되었던 변연 부위 들을 보완하기 위한 목적으로 흡착 의치 제작 시 사용되 는 인상기법을 변형하여 활용하였는데, 우선 $3 \mathrm{D}$ 프린팅 한 시적의치 상에서 부분적으로 변연 수정을 시행하였으 며, 이후 폐구인상법을 사용하여 성공적으로 기능인상과 악간관계 기록 채득을 동시에 완료하였다. ${ }^{10}$ 폐구인상을 활용하여 하악 총의치를 제작할 경우 일반적인 개구인상 과 비교하여 기능 시 유지력이 증가된 의치를 제작할 수 있다는 보고가 있다. ${ }^{10}$ 특히 잔존치조제의 흡수로 인해 사용하던 의치의 유지력이 저하된 환자에게서 재제작이 필요한 경우, 단 2회 정도의 내원만으로 새로운 치조제 형태에 맞는 의치를 $3 \mathrm{D}$ 프린팅으로 완성할 수 있다는 이 점이 있다.

그러나 시적의치를 사용하여 폐구 상태에서 기능인상 채득 시 저작압에 의해 지지영역에 따른 구분 없이 점막 조직에 지속적인 압력이 가해지게 되며, 이러한 방식으 로 제작된 의치는 높은 초기 유지력을 보여주지만 의치 의 압박으로 인해 잔존치조제 흡수가 가속화되어 비교 적 빠르게 의치의 유지력이 감소될 수 있다는 보고가 있 으므로 주의가 필요하다. ${ }^{11}$ 본 증례에서는 낮은 점도의 인상재를 사용하여 기능인상 채득 시 조직에 과하게 가 해지는 압력과 수직고경의 증가를 최소화하였는데, 이는 의치로 인한 부작용을 최소화하기 위해 필수적으로 고려 되어야 할 사항이라 판단된다. 또한 본 증례에서는 통상
적인 총의치와 비교하여 $3 \mathrm{D}$ 프린팅 총의치의 변연이 상 대적으로 얇고 짧게 제작되는 경향이 관찰되었는데 이에 대한 개선이 필요해 보이며, 보다 상용화된 치료술식으 로 자리잡기 위해서는 전통적인 방식에 비해 파절에 취약 한 $3 \mathrm{D}$ 프린팅 의치상의 내구성 향상 및 의치상과 인공치 간의 접착강도 증가와 같은 보완이 요구될 것으로 보여 진다. ${ }^{6,7}$

\section{결론}

본 증례는 전통적인 방식의 총의치 제작과정에서의 스 캔 정보를 활용하여 $3 \mathrm{D}$ 프린팅으로 총의치 제작을 완성 하였으며, 이를 위해 2 회의 추가적인 내원만이 필요하여 환자가 높은 만족도를 보인 치료방법이었다. 전통적인 방식과 $3 \mathrm{D}$ 프린팅 방식으로 제작한 의치의 환자 만족도 및 예후 비교를 위해서는 장기적인 추적검사가 필요할 것으로 판단된다.

\section{ORCID}

Hyun-Min Kim https://orcid.org/0000-0002-4728-3621 Jong-Jin Kim https://orcid.org/0000-0002-2560-7322 Joo-Hee Lee https://orcid.org/0000-0002-7907-3098 Hyun-Suk Cha https://orcid.org/0000-0001-5164-5181 Jin Baik https://orcid.org/0000-0002-3622-3113

\section{References}

1. Oberoi G, Nitsch S, Edelmayer M, Janjic K, Müller AS, Agis H. 3D Printing - Encompassing the Facets of Dentistry. Front Bioeng Biotechnol 2018;6:172.

2. Maeda Y, Minoura M, Tsutsumi S, Okada M, Nokubi T. A CAD/CAM system for removable denture. Part I: fabrication of complete dentures. Int J Prosthodont 1994;7:17-21.

3. Kalberer N, Mehl A, Schimmel M, Müller F, Srinivasan M. CAD-CAM milled versus rapidly prototyped (3D-printed) complete dentures: an in vitro evaluation of trueness. J Prosthet Dent 2019;121:637-43.

4. Yoon HI, Hwang HJ, Ohkubo C, Han JS, Park EJ. Evaluation of the trueness and tissue surface adaptation of CAD-CAM mandibular denture bases manufactured using digital light processing. J Pros- 
thet Dent 2018;120:919-26.

5. Kattadiyil MT, Goodacre CJ, Baba NZ. CAD/ CAM complete dentures: a review of two commercial fabrication systems. J Calif Dent Assoc 2013;41:407-16.

6. Choi JJE, Uy CE, Plaksina P, Ramani RS, Ganjigatti R, Waddell JN. Bond Strength of Denture Teeth to Heat-Cured, CAD/CAM and 3D Printed Denture Acrylics. J Prosthodont 2019;29:415-21.

7. Malik A. Flexural strength, fracture toughness, and denture tooth adhesion of computer aided milled and printed denture bases. Columbus (OH); Ohio State University; 2019. Available from: http://rave.ohiolink.edu/etdc/view?acc_ num $=$ osu1563296646075298 (updated 2020 Jun 30).

8. Park JH, Cho IH, Shin SY, Choi YS. The treatment of an edentulous patient with DENTCA ${ }^{\mathrm{TM}}$ CAD/CAM Denture. J Korean Acad Prosthodont 2015;53:19-25.

9. Goodacre BJ, Goodacre CJ, Baba NZ. Using Intraoral Scanning to Capture Complete Denture Impressions, Tooth Positions, and Centric Relation Records. Int J Prosthodont 2018;31:377-81.

10. Sato K. This is Suction Denture. Seoul; DaehanNarae Publishing Inc.; 2018. p. 54-107.

11. el-Khodary NM, Shaaban NA, Abdel-Hakim AM. Effect of complete denture impression technique on the oral mucosa. J Prosthet Dent 1985;53:543-9. 


\title{
통상적인 총의치 제작과정에서의 스캔 정보를 활용한 three-dimensional printed complete denture의 제작
}

\author{
김현민 ${ }^{1}$ 전공의, 김종진 ${ }^{1}$ 임상교수, 이주희 ${ }^{1}$ 임상교수, ${ }^{2}$ 교수, 차현석 ${ }^{1}$ 임상교수, ${ }^{2}$ 교수, 백진 ${ }^{1 *}$ 임상교수 \\ ${ }^{1}$ 서울아산병원 치과보철과 \\ ${ }^{2}$ 울산대학교 의과대학 서울아산병원 치과보철학교실
}

최근 three-dimensional (3D) printed denture가 완전 무치악 환자의 보철치료 시 선택할 수 있는 하나의 제작 방법으로 주목을 받고 있다. 그러나 아직까지 건강보험 총의치가 $3 \mathrm{D}$ 프린팅 활용을 지원하지 않기 때문에 전통적인 방식만을 사 용해야만 하며, 재제작이 필요할 경우 처음부터 제작과정을 반복해야 한다는 단점이 있다. 그러나 통상적인 의치 제작 과 정 중 특정 단계들의 정보를 디지털 스캔하여 저장할 수 있고, 본 증례에서는 이 정보를 활용하여 통상적인 방식으로 제 작된 첫번째 의치의 문제점을 보완한 새로운 의치를 $3 \mathrm{D}$ 프린팅으로 완성하였다.

(구강회복응용과학지 2020;36(3):196-202)

주요어: 총의치; $3 \mathrm{D}$ 프린팅; 기능인상; 디지털 스캔

*교신저자: 백진

(05505) 서울시 송파구 올림픽로 43길 88 서울아산병원 치과보철과

Tel: 02-3010-5815 | Fax: 02-3010-6967 || E-mail: baikjin@amc.seoul.kr

접수일: 2020년 6월 15일 | 수정일: 2020년 7월 2일 || 채택일: 2020년 7월 23일 